\title{
Glycans as Ligands in Bioinorganic Chemistry. Probing the Interac- tion of a Trinuclear Platinum Anticancer Complex with defined Mon- osaccharide Fragments of Heparan Sulfate
}

\author{
Anil Kumar Gorle, ${ }^{+}$Premraj Rajaratnam, ${ }^{+}$Chih-Wei Chang, ${ }^{+}$Mark von Itzstein, ${ }^{*+}$ Susan J. Berners-Price, ${ }^{*+}$ and \\ Nicholas P. Farrell ${ }^{*+\neq}$ \\ 'Institute for Glycomics, Griffith University, Gold Coast Campus, Southport, Queensland, 4222, Australia. \\ ${ }^{\ddagger}$ Department of Chemistry, Virginia Commonwealth University, Richmond, 23284, Virginia, USA. \\ *s.berners-price@griffith.edu.au; m.vonitzstein@griffith.edu.au; npfarrell@vcu.edu \\ Supporting Information
}

\begin{abstract}
We report herein a detailed NMR study of the aquation and subsequent covalent binding of the trinuclear clinical agent $[\{$ trans$\left.\operatorname{PtCl}\left({ }^{15} \mathrm{NH}_{3}\right)_{2}\right\}_{2}\left\{\mu\right.$-trans-Pt $\left.\left.\left({ }^{15} \mathrm{NH}_{3}\right)_{2}\left({ }^{15} \mathrm{NH}_{2}\left(\mathrm{CH}_{2}\right)_{6}{ }^{15} \mathrm{NH}_{2}\right)_{2}\right\}\right]^{4+}(\mathbf{1}, 1,0,1 / t, t$, t or Triplatin $)$ with three D-glucosamine residues containing varied $\mathrm{O}$-sulfate and $\mathrm{N}$-sulfate or $\mathrm{N}$-acetyl substitutions, which represent monosaccharide fragments present within the repeating disaccharide sequences of cell surface heparan sulfate (HS). The monosaccharides GlcNS(6S), GlcNS and GlcNAc(6S) were synthesized in good yields from a common 4,6-diol $\alpha$-methyl glucopyranoside intermediate. The reactions of ${ }^{15} \mathrm{~N}$-1 with sodium sulfate, GlcNS(6S), GlcNS and GlcNAc(6S) were followed by $\left[{ }^{1} \mathrm{H},{ }^{15} \mathrm{~N}\right]$ HSQC $2 \mathrm{D}$ NMR spectroscopy using conditions $(298 \mathrm{~K}, \mathrm{pH} \approx 5.4)$ similar to those previously used for other anionic systems, allowing for a direct comparison. The equilibrium constants $\left(\mathrm{p} K_{1}\right)$ for the aquation of $\mathbf{1}$ in the presence of GlcNS(6S) and GlcNS are slightly higher compared to that of the aquation in sulfate solution, while a comparable $\mathrm{p} K_{1}$ value is observed in the presence of GlcNAc(6S). Comparison of the rate constants for sulfate displacement of the aqua ligand show preferential binding to 2- $\mathrm{N}$-compared to 6-O-sulfate, but a more rapid liberation. For the disulfated GlcNS $(6 \mathrm{~S})$, the equilibrium conditions are achieved rapidly $(9 \mathrm{~h})$ and strongly favor the dichloro form, with $<2 \%$ sulfato species observed. The value of $k_{\mathrm{L} 1}$ is up to 15 -fold lower than for binding to sulfate, whereas the rate constant for the reverse ligation $\left(k_{\mathrm{L} 1}\right)$ is comparable. Equilibrium conditions were achieved much more slowly $(\sim 100 \mathrm{~h})$ for the reactions of $\mathbf{1}$ with GlcNS and Glc$\mathrm{NAc}(6 \mathrm{~S})$, attributed to covalent binding also to the $\mathrm{N}$-donor of the sulfamate (GlcNS) and $O$-donor of the $N$-acetyl (GlcNAc(6S)) groups. The rate constants $\left(k_{\mathrm{L} 2}\right)$ are 20-40 fold lower than for binding to the 2- $\mathrm{N}$ - or 6-O-sulfate, but the binding is less reversible so that their equilibrium concentrations (5-8\%) are comparable to the 2-N- or 6-O-sulfate bound species. The results emphasise the relevance of glycans in bioinorganic chemistry and underpin a fundamental molecular description of the HS-Pt interactions that alter the profile of platinum agents from cytotoxic to metastatic in a systematic manner.
\end{abstract}

\section{INTRODUCTION}

Sugars are considered the most abundant class of organic molecules and are the third major class of biomolecules after proteins and nucleic acids. Glycomics is a broad scientific discipline elucidating the diverse array of structure and function of glycans in biological systems. ${ }^{1,2}$ Glycosaminoglycans (GAGs) play a role in a vast number of biological events including cellular adhesion and migration, angiogenesis and the modulation of immunological responses and also act as receptors for bacterial and viral pathogen adhesion and invasion to host cells. GAGs are highly anionic and, as with DNA or RNA, are associated with endogenous inorganic cations in nature. The details of metal ion-biomolecule interactions are of fundamental importance in understanding the roles of metal ions in biology. Study of individual amino acid and purine and pyrimidine nucleic acid bases have contributed significantly to the understanding of the kinetics and thermodynamics of metal complex $(M)$ protein and $M$ DNA(RNA) interactions of biological significance. Yet, as the third major class of biomolecules, the bioinorganic chemistry of glycans in the broadest sense is significantly less developed than that of proteins and nucleic acid interactions. ${ }^{1,2}$
Chart 1. Major repeating disaccharide unit (a) and variable repeating disaccharide unit (b) of heparan sulfate (HS).

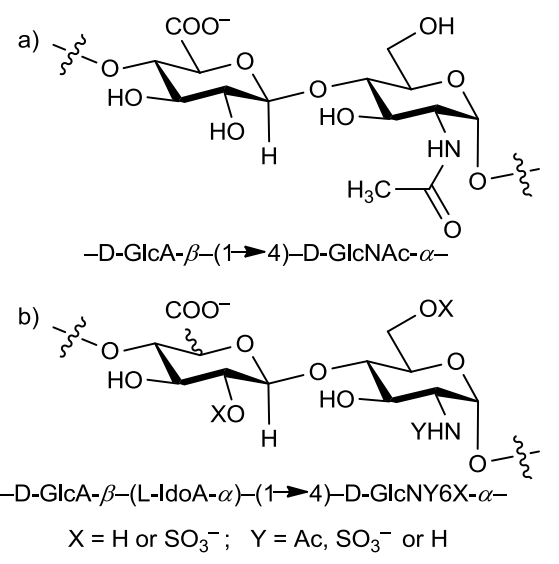

Metalloglycomics - a term first coined by $\operatorname{Codd}^{3}$ - is the systematic study of the effects of metal ions and coordination compounds on oligosaccharides. ${ }^{4}$ The $\mathrm{O}$-donor polyanions of glycan biomole- 
cules may be receptors and possible targets in their own right for coordination compounds. ${ }^{4}$ Examples include the interaction of $\mathrm{Cr}(\mathrm{V})$ compounds with sialic acids and its relevance to toxicity and metabolism of Cr species ${ }^{3,5,6}$ and the use of Ru-bipyridines as fluorescent probes of heparin concentration. ${ }^{7-10} \mathrm{Co}(\mathrm{III})$-ammine complexes have also been proposed for quantification of sulfated glycans including in clinical studies. ${ }^{11-13}$ These apparently disparate examples testify to the broad relevance of metalloglycomics. Glycans offer a wide variety of binding possibilities from purely carboxylate-based (sialic acid and hyaluronan) to the mixed carboxylated and sulfated glycosaminoglycans (GAGs) including heparin and heparan sulfate (HS) and the related dermatan and chondroitin sulfates. ${ }^{14} \mathrm{HS}$ sequences consist of repeating $1 \rightarrow 4$ linked disaccharide units of D-glucosamine and glucuronic or iduronic acid residues that are variably substituted by sulfate or acetyl groups at the 2-N, and sulfate at the 6-O positions of $\mathrm{D}$-glucosamine and by sulfate at the $2-O$ position of, predominantly, iduronic acid (Chart 1 ). To understand the full potential of metalloglycomics and the molecular details of glycan bioinorganic chemistry, basic studies on the mono and disaccharide components are necessary, in much the same way that early M-DNA chemistry was concentrated on single purine and pyrimidine chemistry to understand nucleobase/nucleoside/nucleotide preferences. The detailed mechanistic study of the role of HS in biology in general is hampered by limited access to defined site-specific oligosaccharides. In this paper we present novel synthetic methods for the preparation of site-specific oligosaccharides and the first examples of the effect of site-specific glycan substitution on the kinetics of binding to clinically relevant platinum antitumor agents using $\left[{ }^{1} \mathrm{H},{ }^{15} \mathrm{~N}\right]$ HSQC 2D NMR spectroscopy, the first example of use of this technique in glycan bioinorganic chemistry. ${ }^{15}$

We have chosen to study polynuclear platinum complexes (PPCs) as an excellent example (case study) because we have shown that positively charged PPCs interfere with heparan sulfate (HS) function through strong binding of the highly charged PPCs to the HS backbone with potential for development of anti-metastatic, rather than cytotoxic, properties. ${ }^{14,16}$ As a soft acid Pt is expected to form coordination bonds easily with $S$ and/or $N$-donors, but chemically weak ligand interactions with oxygen donors can be favoured due to higher concentrations in the biological milieu. In one sense, these glycans represent an extension from simple individual $O$-donors to multiple donor sites on a more complex polymeric, biomolecular template with multiple possible binding sites. Heparin is considered to have the highest negative charge density of any known biomolecule with an average of approximately 3 negative charges per disaccharide. ${ }^{17-19}$

To date, the molecular mechanism of action of platinum drugs has focused on their interactions with DNA as target. Metabolic interactions with proteins, especially Human Serum Albumin, and small peptides such as glutathione are considered deactivating. Detailed pathways for interaction with nucleic acids and proteins $(N$ and/or $S$ donors) are by now well documented. The vast majority of discussion on cellular formation of cisplatin-DNA adducts focusses on the monoaqua or diaqua species produced upon intracellular aquation of the $\mathrm{Pt}-\mathrm{Cl}$ bonds. Interactions with $\mathrm{O}$-donor groups as bases have not been considered as essential to explain cisplatin activity - in part because their hard nature is less compatible with the soft acid characteristics of $\mathrm{Pt}$, noting that $\mathrm{Pt}-\mathrm{OH}$ bonds can be quite strong. Depending on extracellular and intracellular concentrations however these weak anions - carboxylate, carbonate, phosphate and sulfate - should be considered as potential ligands in the cellular and biological milieu. Appleton showed that buffer solutions containing acetate or phosphate may contain significant concentrations of acetate/phosphate adducts which could affect interpretation of kinetic results. ${ }^{20} \mathrm{~A}$ further case in point is that of carbonate where the formation of carbonato-platinum intermediates has been proposed as a possible mechanism of cellular accumulation of cisplatin..$^{21-25}$ Indeed, even the substitution-inert carboplatin can undergo biotransformation reactions including ring-opening of the dicarboxylate ligand in the presence of physiological concentrations of $\mathrm{CO}_{3}{ }^{2-22,23}$ These transformation reactions have been observed in cells and platinumcarbonato species may have a role in the cytotoxicity, accumulation and even resistance mechanisms of cisplatin and carboplatin. ${ }^{24,25}$ Carbonate may also activate the formally inert bidentate malonate ligand in $[\mathrm{Pt}(\mathrm{dach})$ (malonato) $] .{ }^{26}$ Intracellular biotransformation of the malonate compound in L1210 cells showed the presence of minor species containing arginine, glutamate and aspartate along with those from the expected $S$-donor ligands methionine, cysteine and glutathione..$^{27}$ Biotransformation of the clinically relevant oxaliplatin in L1210 cells also showed the presence of $O$-bound metabolites including even citrate species. ${ }^{27,28}$ Finally, interactions of sulfate at physiologically relevant concentrations have been observed for cisplatin $^{29}$ and dinuclear platinum agents. ${ }^{30}$ While many of these identified species may be transitory and not affect final interaction with DNA, nevertheless a full description of these interactions is required.

Chart 2. Structures of (a) the polynuclear platinum complexes $1,0,1 / t, t, t(1$, Triplatin) and $1,1 / t, t$ and (b) the three D-glucosamine monosaccharide $H S$ fragments used in the present study.
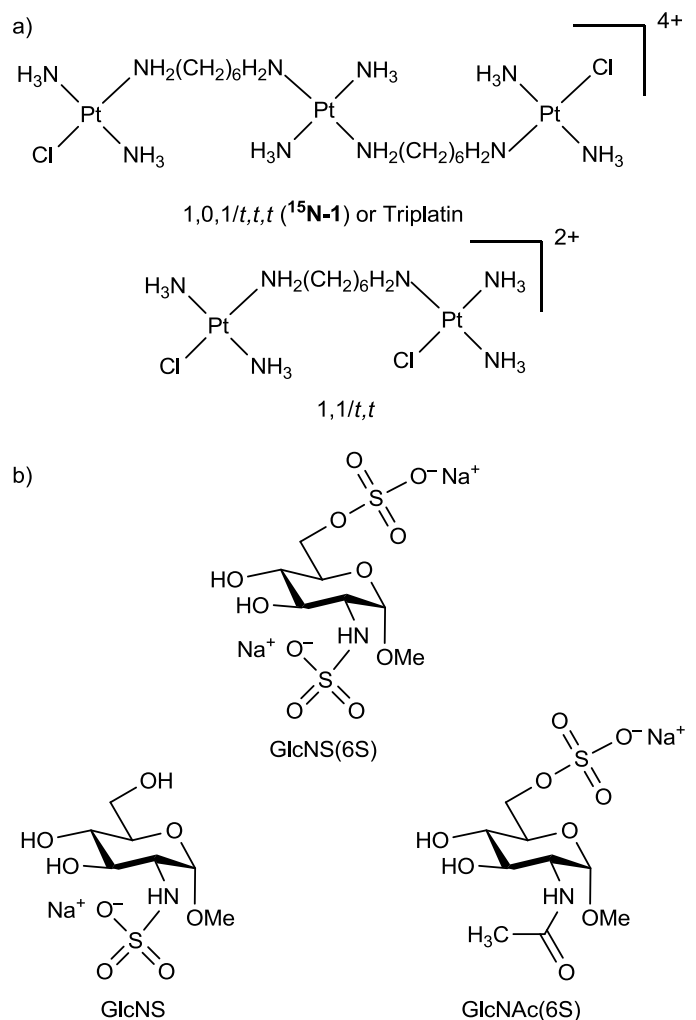

In this paper, we study the aquation and subsequent covalent binding of the ${ }^{15} \mathrm{~N}$-labeled trinuclear clinical agent Triplatin $(1,0,1 / t, t, t, \mathbf{1})$ with sulfate anion, as well as three monosaccharide fragments of D-glucosamine residues with variable sulfate and acetyl 
substitution at the $2-\mathrm{N}$ and $6-\mathrm{O}$ positions [GlcNS(6S):2-N and 6-O sulfated; GlcNS: $2-N$ sulfated; GlcNAc(6S): 2-N acetylated and 6$O$ sulfated] (Chart 2) as representative $\mathrm{D}$-glucosamine fragments of HS. The conditions used allow direct comparison of the derived rate and equilibrium constants with those obtained for reaction of $\mathbf{1}$ in phosphate solution, ${ }^{31}$ and also for the reactions of the dinuclear ana$\log 1,1 / t, t$ (Chart 2) with acetate, phosphate ${ }^{32}$ and sulfate, ${ }^{30}$ allowing the influence of the charged $\left\{\mathrm{PtN}_{4}\right\}^{2+}$ central linker of $\mathbf{1}$ to be explored.

\section{RESULTS}

The synthesis of three D-glucosamine monosaccharide HS fragments with variable substitution at the $2-\mathrm{N}$ and $6-\mathrm{O}$ positions has been achieved in good yields following the synthetic route shown in Scheme 1. The common 4,6-diol $\alpha$-methyl glucopyranoside (A), which was used as a starting material to synthesize the final monosaccharide fragments, was prepared in five steps starting from readily available glucosamine hydrochloride following literature procedures. ${ }^{33,34}$ Hydrogenolysis of diol $\mathbf{A}$ using $\mathrm{Pd}(\mathrm{OH})_{2}$ on active carbon under a hydrogen atmosphere provided methyl 2-amino-2-deoxy- $\alpha$ D-glucopyranoside as a pale yellow oil, which was then treated with sulfur trioxide trimethylamine complex and triethylamine in water/methanol $(1: 1 \mathrm{v} / \mathrm{v})$. This mixture was heated under microwave irradiation at $80^{\circ} \mathrm{C}$ for 20 minutes, over three cycles, affording the crude compound $\mathbf{B}$. Purification of the product by size-exclusion chromatography (SEC) and subsequent passage through a cation exchange column, provided a mixture of compound $\mathbf{B}$ contaminated with inseparable sodium methyl sulfate. Formation of this undesired byproduct was successfully avoided by changing the solvent from $1: 1$ methanol/water to $100 \%$ water, resulting in isolation of pure 2$\mathrm{N}$-sulfated D-glucosamine (product B) in quantitative yield (purity $>95 \%$, determined by ${ }^{1} \mathrm{H} \mathrm{NMR}$ ), which is superior to the previously reported method in the literature. ${ }^{35}$

Scheme 1. Synthesis of D-glucosamine monosaccharide HS fragments. ${ }^{a}$

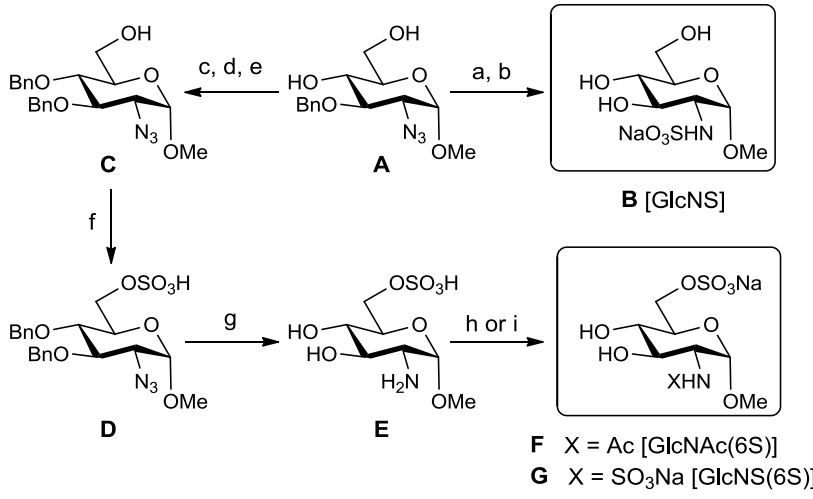

${ }^{a}$ Reagents and conditions: a) $\mathrm{H}_{2}, \mathrm{Pd}(\mathrm{OH})_{2} / \mathrm{C}, \mathrm{EtOH} /$ phosphate buffer (1:1 v/v), 15 h; b) $\mathrm{SO}_{3} . \mathrm{NMe}_{3}, \mathrm{NEt}_{3}, \mathrm{H}_{2} \mathrm{O}, 80^{\circ} \mathrm{C}, \mathrm{MW}, 20$ min, 3 cycles; c) $\mathrm{NEt}_{3}$, DMAP, TBDPSCl, DMF, RT, $15 \mathrm{~h}$; d) $\mathrm{BnBr}, 60 \% \mathrm{NaH}, 0{ }^{\circ} \mathrm{C}$ to RT, $6 \mathrm{~h}$ (one-pot 2 steps); e) $1 \mathrm{M} \mathrm{TBAF}$ in THF, $50{ }^{\circ} \mathrm{C}, 15 \mathrm{~h}$; (75\% yield over 3 steps from compound $\mathbf{A}$ to $\mathbf{C}$ ); f) $\mathrm{SO}_{3} \cdot \mathrm{NMe}_{3}$, DMF, $75{ }^{\circ} \mathrm{C}, 1 \mathrm{~h}$; g) $\mathrm{H}_{2}$, $\mathrm{Pd}(\mathrm{OH})_{2} / \mathrm{C}, \mathrm{EtOH} /$ phosphate buffer $(1: 1 \mathrm{v} / \mathrm{v}), 15 \mathrm{~h}$; h) $\mathrm{Ac}_{2} \mathrm{O}, \mathrm{NEt}_{3}$, $\mathrm{MeOH} / \mathrm{H}_{2} \mathrm{O}$ (1:1 v/v); i) $\mathrm{SO}_{3} . \mathrm{NMe}_{3} \mathrm{NEt}_{3}, \mathrm{H}_{2} \mathrm{O}, 80^{\circ} \mathrm{C}, \mathrm{MW}, 20$ min, 3 cycles.

Further, compound $\mathbf{A}$ was subjected to one-pot 6-O-TBDPS protection and 4-O-benzylation, followed by subsequent desilylation using TBAF to obtain compound $\mathbf{C}$ in $75 \%$ yield over three steps. Sulfation at the 6-O position of $\mathbf{C}$ was readily achieved by heating a mixture of $\mathbf{C}$ and sulfur trioxide trimethylamine complex in $\mathrm{DMF}$ at $75^{\circ} \mathrm{C}$ for $1 \mathrm{~h}$, giving $\mathbf{D}$. Hydrogenolysis of the benzyl ethers and azide of $\mathbf{D}$ afforded the fully-deprotected 6-O-sulfated 2-amino derivative $\mathbf{E}$ in quantitative yield. The product $\mathbf{E}$ was divided into two equal portions. One portion was used for chemoselective $N$ acetylation using acetic anhydride and triethylamine to obtain the final 2- $\mathrm{N}$ acetylated 6-O-sulfated D-glucosamine product F. The other portion was subjected to $N$-sulfation conditions to synthesize the 2$N$ and 6-O di-sulfated D-glucosamine product G. Upon purification of the crude mixtures, compound $\mathbf{F}$ and $\mathbf{G}$ were obtained in $53 \%$ and $40 \%$ yields, respectively. The exclusive sulfation positions and high purity of the monosaccharide units $\mathbf{B}, \mathbf{E}, \mathbf{F}$ and $\mathbf{G}$ were confirmed by high-resolution mass spectrometry (HRMS) and ${ }^{1} \mathrm{H}$ - and ${ }^{13} \mathrm{C}-\mathrm{NMR}$ spectroscopy.

NMR Studies. The aquation reactions of ${ }^{15} \mathrm{~N}-1(1 \mathrm{mM})$ in $15 \mathrm{mM}$ sodium sulfate solution ( $\mathrm{pH} \mathrm{5.4)}$ and in the presence of the three sulfated glucosamine residues ( $\mathbf{B}, \mathbf{F}$ and $\mathbf{G} ; 1: 15 \mathrm{~mol}$ ratio, $\mathrm{pH} \sim 5.4$ ) at $298 \mathrm{~K}$ were followed by $2 \mathrm{D}\left[{ }^{1} \mathrm{H},{ }^{15} \mathrm{~N}\right]$ HSQC NMR spectroscopy. The conditions are similar to those used previously for reaction of $\mathbf{1}$ in phosphate solution ( $15 \mathrm{mM}),{ }^{31}$ and also for the reactions of dinuclear $1,1 / t, t$ with acetate, phosphate $e^{32}$ and sulfate, ${ }^{30}$ thus allowing for a direct comparison. The $\left[{ }^{1} \mathrm{H},{ }^{15} \mathrm{~N}\right]$ NMR method requires that studies are conducted below physiological $\mathrm{pH}$ in these systems as it depends on a measurable ${ }^{1} J\left({ }^{15} \mathrm{~N}-{ }^{1} \mathrm{H}\right)$ spin-spin coupling. ${ }^{15}$ Representative $\left[{ }^{1} \mathrm{H},{ }^{15} \mathrm{~N}\right]$ HSQC NMR spectra recorded for equilibrium solutions of the four reactions are shown in Figure 1 and the ${ }^{1} \mathrm{H}$ and ${ }^{15} \mathrm{~N}$ chemical shifts of the ${ }^{15} \mathrm{NH}_{3}$ and ${ }^{15} \mathrm{NH}_{2}$ groups of the different species observed (see Scheme 2) are listed in Table 1.

Scheme 2. Simplified kinetic models used to the study the aquation of $1,0,1 / t, t, t(1)$ in the presence of sodium sulfate and the three D-glucosamine monosaccharide HS fragments. ${ }^{a}$
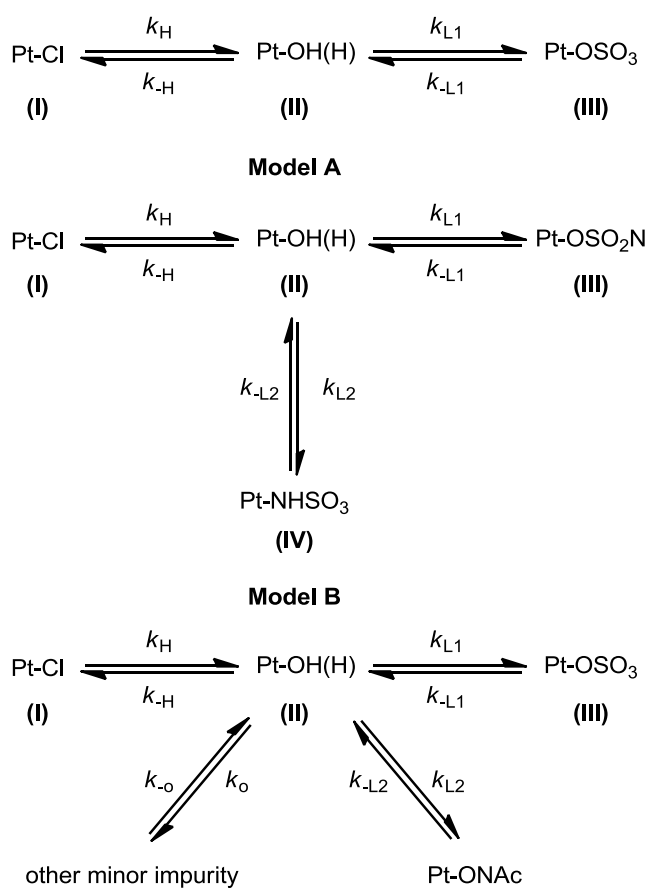

(O)

Model C

(V)

a Roman numerals represent the mononuclear species [trans$\left[\mathrm{Pt}\left(\mathrm{NH}_{3}\right)_{2}\left(\mathrm{NH}_{2}\left(\mathrm{CH}_{2}\right)_{6} \mathrm{NH}_{2}\right) \mathrm{Y}\right]^{\mathrm{n}+}(\mathrm{Pt}-\mathrm{Y})$ where $\mathrm{Y}$ represents the coordinated ligand $\mathrm{Cl}, \mathrm{H}_{2} \mathrm{O}, \mathrm{SO}_{4}$ etc. Model A was used for sulfate and $\mathrm{GlcNS}(6 \mathrm{~S})$; Model B for GlcNS and Model C for GlcNAc(6S). 

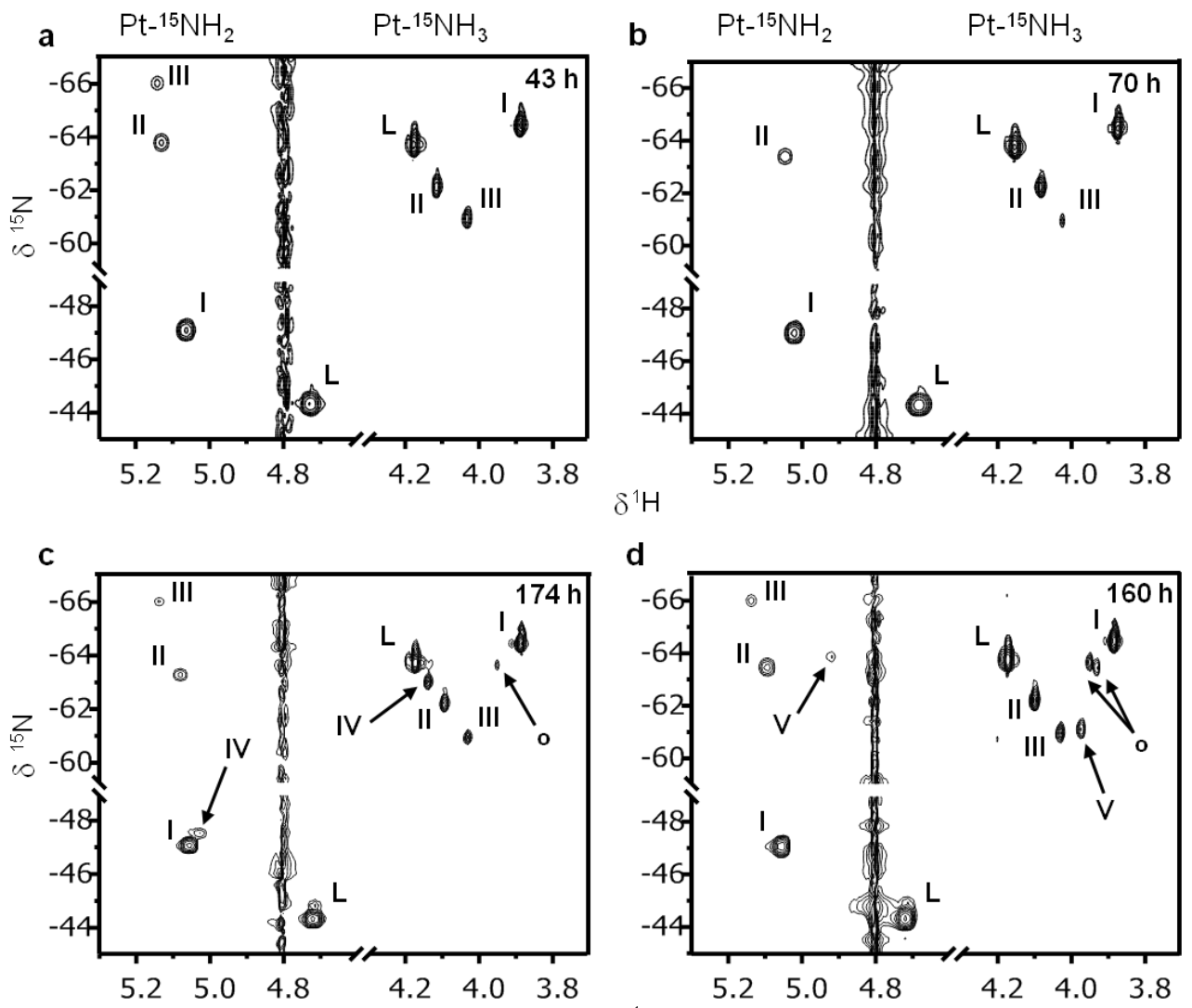

d

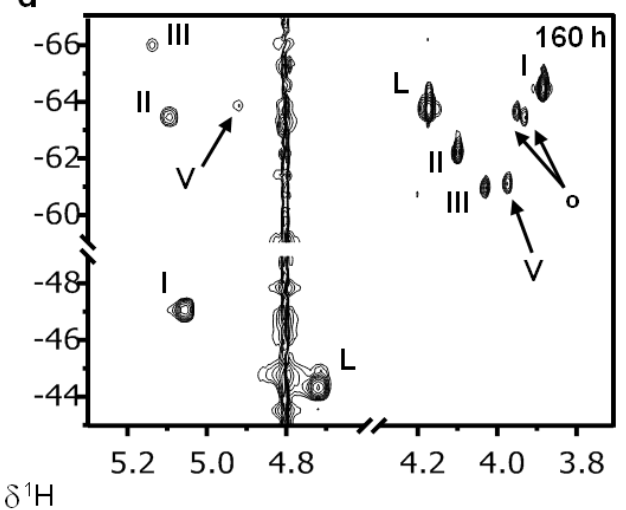

Figure 1.2D $\left[{ }^{1} \mathrm{H},{ }^{15} \mathrm{~N}\right]$ HSQC NMR $(600 \mathrm{MHz})$ spectra of $1,0,1 / t, t, t(\mathbf{1})$ after reaction with a) $15 \mathrm{mM}$ sodium sulfate at $298 \mathrm{~K}$ (pH 5.4) after 43 h; b) GlcNS(6S) at $298 \mathrm{~K}\left(\mathrm{pH} 5.3\right.$ ) after $70 \mathrm{~h}$; c) GlcNS at $298 \mathrm{~K}(\mathrm{pH} 5.4)$ after $174 \mathrm{~h}$; d) GlcNAc(6S) at 298K (pH 5.3) after 160 h. Peaks have been assigned to the Pt- ${ }^{15} \mathrm{NH}_{3}$ and Pt $-{ }^{15} \mathrm{NH}_{2}$ groups of the species shown in Scheme 2 Model A (a and b), Model B (c) and Model C (d). Peak assignments are shown in Table 1. Peaks labeled "L" are from the $\mathrm{Pt}^{-15} \mathrm{NH}_{3}$ and $\mathrm{Pt}^{-15} \mathrm{NH}_{2}$ groups of the central $\left\{\mathrm{PtN}_{4}\right\}^{2+}$ linker and "o" are other minor products (see text).

Table 1. ${ }^{1} \mathrm{H}$ and ${ }^{15} \mathrm{~N}$ Chemical Shifts for the $\mathrm{Pt}-{ }^{15} \mathrm{NH}_{3}$ and $\mathrm{Pt}-$ ${ }^{15} \mathrm{NH}_{2}$ Groups of the Species Observed During the Reaction of ${ }^{15}$ N-1 with Sulfate, GlcNS $(6 S)$, GlcNS and GlcNAc $(6 S)$ at $298 \mathrm{~K}$, $\mathrm{pH} \sim 5.4 .^{a}$

\begin{tabular}{lcccc}
\hline \multirow{2}{*}{$1,0,1 / t, t, t$ species } & \multicolumn{2}{c}{${ }^{15} \mathrm{NH}_{3}$} & \multicolumn{2}{c}{${ }^{15} \mathrm{NH}_{2}$} \\
\cline { 2 - 5 } & $\delta^{1} \mathrm{H}$ & $\delta^{15} \mathrm{~N}$ & $\delta^{1} \mathrm{H}$ & $\delta^{15} \mathrm{~N}$ \\
\hline $\mathbf{I}(\mathrm{Pt}-\mathrm{Cl})$ & 3.88 & 64.4 & 5.05 & 47.1 \\
$\mathbf{I I}(\mathrm{Pt}-\mathrm{OH}(\mathrm{H}))^{b}$ & 4.09 & 62.2 & 5.07 & 63.3 \\
$\mathbf{I I I}\left(\mathrm{Pt}-\mathrm{OSO}_{3} / \mathrm{OSO}_{2} \mathrm{~N}\right)^{c}$ & 4.03 & 60.9 & 5.14 & 66.0 \\
$\mathbf{I V}\left(\mathrm{Pt}-\mathrm{NHSO}_{3}\right)$ & 4.13 & 63.0 & 5.02 & 47.5 \\
$\mathbf{V}(\mathrm{Pt}-\mathrm{ONAc})$ & 3.97 & 61.1 & 4.92 & 63.9
\end{tabular}

${ }^{a 1} \mathrm{H}$ referenced to $1,4-$ dioxane (internal) and ${ }^{15} \mathrm{~N}$ referenced to ${ }^{15} \mathrm{NH}_{4} \mathrm{Cl}$ (external). Roman numerals represent the mononuclear species [trans$\left[\mathrm{Pt}\left(\mathrm{NH}_{3}\right)_{2}\left(\mathrm{NH}_{2}\left(\mathrm{CH}_{2}\right)_{6} \mathrm{NH}_{2}\right) \mathrm{Y}\right]^{\mathrm{n}+}$ as shown in the kinetic models in Scheme 2. Only the shifts for the terminal Pt-am(m)ine groups are listed; the ${ }^{1} \mathrm{H},{ }^{15} \mathrm{~N}$ shifts of the linker group were unchanged over the course of any of the reactions, but ${ }^{1} \mathrm{H}$ shifts were slightly shielded for the reaction with $\mathrm{GlcNS}(6 \mathrm{~S})(\delta$ 4.15/-63.7 $\left(\mathrm{NH}_{3}\right)$ and 4.68/-44.3 $\left.\left(\mathrm{NH}_{2}\right)\right)$ compared to reaction with sulfate and the other two monosaccharides $\left(\delta 4.17 /-63.7\left(\mathrm{NH}_{3}\right)\right.$ and $4.72 /-44.3$ $\left.\left(\mathrm{NH}_{2}\right)\right) \cdot{ }^{1} \mathrm{H} /{ }^{15} \mathrm{~N}$ chemical shifts for the aquation product are $\mathrm{pH}$ sensitive; for titration curves see ref. ${ }^{31}$ Identical ${ }^{1} \mathrm{H} /{ }^{15} \mathrm{~N}$ chemical shifts for the sulfate bound species were observed in all cases.
Aquation of 1 in Sulfate Solution. In addition to the ${ }^{1} \mathrm{H} /{ }^{15} \mathrm{~N}$ crosspeaks at $\delta 3.89 /-64.4\left(\mathrm{NH}_{3}\right)$ and 5.06/-47.0 $\left(\mathrm{NH}_{2}\right)$ corresponding to the parent dichloro species ( $\mathrm{Pt}-\mathrm{Cl}$, label $\mathbf{I}$, Figure 1a), peaks assignable to the aquated species $\left(\mathrm{Pt}-\mathrm{OH}_{2}\right.$, label II, Figure 1a) appeared at $\delta 4.11 /-62.1\left(\mathrm{NH}_{3}\right)$ and 5.13/-63.7 $\left(\mathrm{NH}_{2}\right)$. Two additional peaks at $\delta$ 4.03/-60.9 $\left(\mathrm{NH}_{3}\right)$ and 5.14/-66.0 $\left(\mathrm{NH}_{2}\right)$ became visible as the reaction proceeded and are assigned to the sulfato species ( $\mathrm{Pt}-\mathrm{OSO}_{3}$, label III, Figure 1a). The chemical shifts for the terminal ${ }^{15} \mathrm{NH}_{3}$ and ${ }^{15} \mathrm{NH}_{2}$ groups are identical to those observed for the reaction of $1,1 / t, t$ with sulfate. ${ }^{30}$ The ${ }^{1} \mathrm{H} /{ }^{15} \mathrm{~N}$ chemical shifts of the linker ${ }^{15} \mathrm{NH}_{3}$ and ${ }^{15} \mathrm{NH}_{2}$ groups did not change over the course of the reaction (Table 1$)$.

Similar to the reaction with $1,1 / t, t$, the system in sulfate solution reached equilibrium after $12 \mathrm{~h}$. The majority (64.7\%) of 1 remained in the chloro form $(\mathrm{Pt}-\mathrm{Cl}, \mathbf{I})$, with the aquated $\left(\mathrm{Pt}_{-}-\mathrm{OH}_{2}, \mathbf{I I}\right)$ and sulfato species $\left(\mathrm{Pt}-\mathrm{OSO}_{3}, \mathrm{III}\right)$ accounting for $24.0 \%$ and $11.3 \%$, respectively. The kinetic profile for the reaction is shown in Figure $2 \mathrm{a}$ and the rate and equilibrium constants are summarized in Table 2 and compared with the values obtained for reaction of $\mathbf{1}$ with phosphate and for $1,1 / t, t$ with sulfate, phosphate and acetate under the same conditions. ${ }^{30-32}$ While the reaction of $1,1 / t, t$ with sulfate has a similar distribution at equilibrium (I, 68.4\%, II, 20.9, III, 10.7\%), inspection of the rate constants in Table 2 reveals interesting differences that may be attributed to a balance of ion pairing $\left(\mathrm{Cl}^{-}\right)$and/or formation of sulfate (or phosphate) clamps with the charged $\left\{\mathrm{PtN}_{4}\right\}^{2+}$ central linker. For aquation in the absence of coordinating anions the equilibrium constant for the aquation $\left(\mathrm{p} K_{1}\right)$ is lower for $\mathbf{1}$ than 

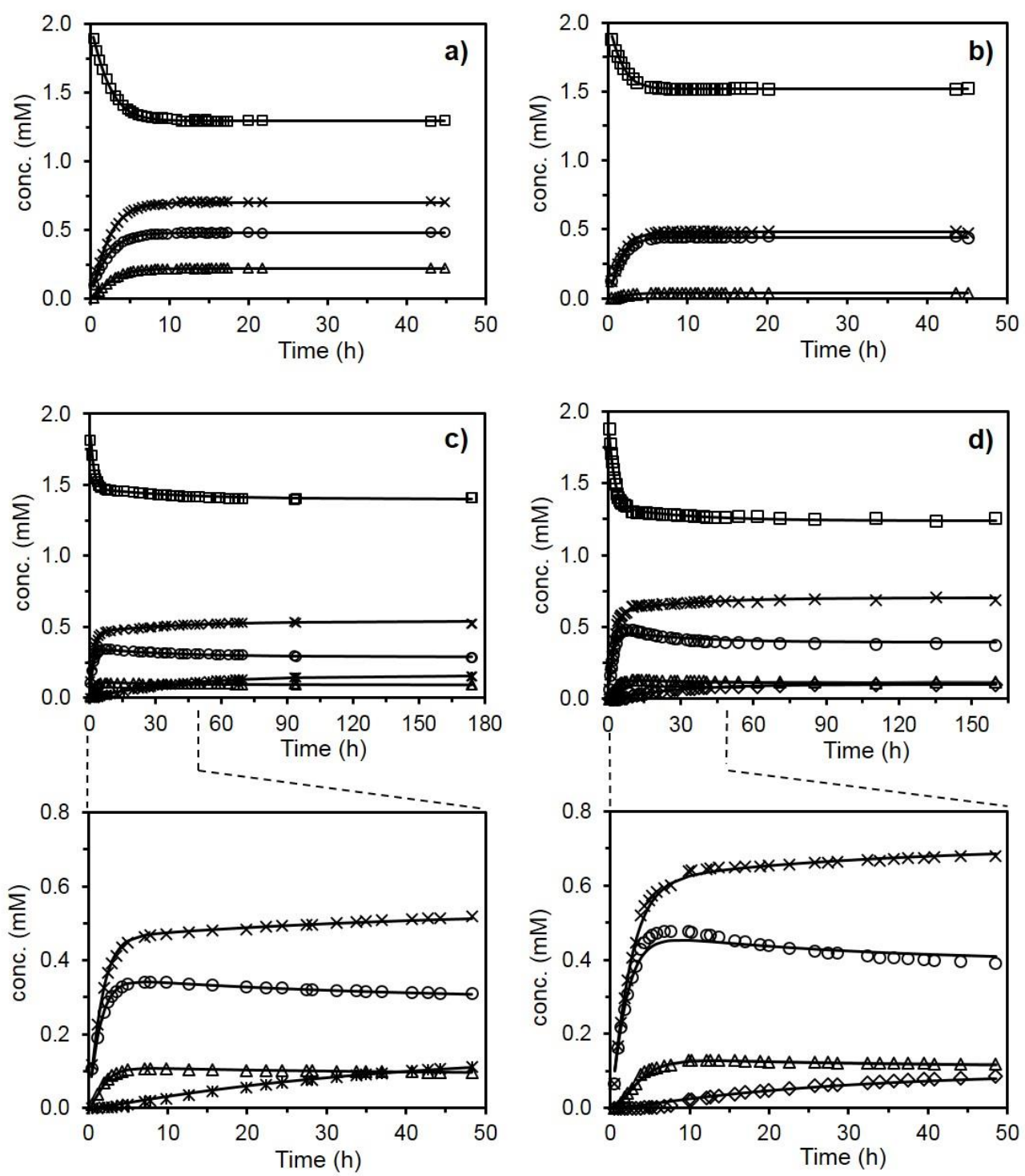

Figure 2. Plots of relative concentrations of species observed during the reaction of 1,0,1/t,t,t (1) at $298 \mathrm{~K}$ with a) sodium sulfate ( $\mathrm{pH} 5.4$ ); b) GlcNS(6S) (pH 5.3); c) GlcNS (pH 5.4); d) GlcNAc(6S) (pH 5.3), based on intensities of the crosspeaks in the $\mathrm{Pt}^{15} \mathrm{NH}_{3}$ region of the $2 \mathrm{D}\left[{ }^{1} \mathrm{H},{ }^{15} \mathrm{~N}\right] \mathrm{HSQC}$ spectra (Figure 1 ). The curves are computer best fits for the rate constants shown in Tables 2 and 3, which were fit to Model A (a and b); Model B (c); Model C (d) (Scheme 2). Key I is open squares ( $\square)$; $\mathrm{Cl}^{-}$is " $\mathrm{x}$ "; $\mathbf{I I}$ is open circles $(\mathrm{O})$; III is open triangles $(\Delta)$; IV is asterisks $(\mathrm{x})$; $\mathbf{V}$ is open diamonds $(\diamond)$. In $(\mathrm{d})$ the other minor products ('o') are not shown for clarity but were included in the kinetic model (see Table 3 ).

Table 2. Rate and Equilibrium Constants for the Aquation and Ligation of $1,1 / t, t^{a}$ and $1,0,1 / t, t, t^{b}(1)$ in $15 \mathrm{mM}$ Sulfate, Acetate and Phosphate.

\begin{tabular}{|c|c|c|c|c|c|}
\hline \multirow{2}{*}{ Parameter } & \multicolumn{2}{|c|}{$1,0,1 / t, t, t\left({ }^{15} \mathrm{~N}-\mathbf{1}\right)^{a}$} & \multicolumn{3}{|c|}{$1,1 / t, t^{b}$} \\
\hline & $\mathrm{SO}_{4}{ }^{2-}$ & $\mathrm{PO}_{4}{ }^{3-}$ & $\mathrm{SO}_{4}{ }^{2-}$ & $\mathrm{PO}_{4}{ }^{3^{-}}$ & $\mathrm{OAc}^{-}$ \\
\hline$k_{\mathrm{H}}\left(10^{-5} \mathrm{~s}^{-1}\right)$ & $3.43 \pm 0.01$ & $3.4 \pm 0.1$ & $3.85 \pm 0.05$ & $2.49 \pm 0.04$ & $1.83 \pm 0.03$ \\
\hline$k_{-\mathrm{H}}\left(\mathrm{M}^{-1} \mathrm{~s}^{-1}\right)$ & $0.1324 \pm 0.0007$ & $0.275 \pm 0.009$ & $0.229 \pm 0.04$ & $0.40 \pm 0.01$ & $0.262 \pm 0.009$ \\
\hline$k_{\mathrm{L} 1}\left(\mathrm{M}^{-1} \mathrm{~s}^{-1}\right)$ & $0.0131 \pm 0.0006$ & $0.0166 \pm 0.0002$ & $0.025 \pm 0.004$ & $0.0086 \pm 0.0002$ & $0.0086 \pm 0.0001$ \\
\hline$k_{\text {-L } 1}\left(10^{-5} \mathrm{~s}^{-1}\right)$ & $41 \pm 2$ & $5.4 \pm 0.1$ & $70 \pm 10$ & $3.9 \pm 0.1$ & $0.56 \pm 0.02$ \\
\hline $\mathrm{p} K_{1}$ & $3.587 \pm 0.003$ & $3.73 \pm 0.02$ & $3.77 \pm 0.01$ & $4.21 \pm 0.02$ & $4.16 \pm 0.02$ \\
\hline $\mathrm{p} K_{2}$ & $-1.50 \pm 0.03$ & $-2.51 \pm 0.01$ & $-1.6 \pm 0.1$ & $-2.34 \pm 0.02$ & $-3.19 \pm 0.02$ \\
\hline
\end{tabular}

${ }^{a}$ Data for ${ }^{15} \mathrm{~N}-1$ binding with $\mathrm{PO}_{4}{ }^{3-}$ taken from ref. ${ }^{31} \cdot{ }^{b}$ Data taken from ref..$^{30,32}$. 
the related dinuclear complex (i.e. further toward the aquated species) due to a lower anation $\left(k_{-\mathrm{H}}\right)$ rate constant, attributed to ionpairing between chloride ions and the $\left\{\mathrm{PtN}_{4}\right\}^{+}$unit. ${ }^{31}$ For the reactions in sulfate the two $\mathrm{p} K_{1}$ values are comparable, as a consequence of a slightly lowered forward rate constant $\left(k_{\mathrm{H}}\right)$ for $\mathbf{1}$, and two-fold lower anation rate constant $\left(k_{-\mathrm{H}}\right)$ for the reformation of the chloro species. A similar two-fold lowering of $k_{-\mathrm{H}}$ is seen for the reactions in phosphate, but in this case the aquation rate constant is 1.4 times higher for the trinuclear complex, resulting in a significantly lower $\mathrm{p} K_{1}$ value. For $1,1 / t, t$ the $\mathrm{p} K_{1}$ value in sulfate is almost 0.5 log units lower compared to that in either phosphate or acetate, but for trinuclear $\mathbf{1}$, the $\mathrm{p} K_{1}$ values in sulfate and phosphate are comparable. The rate constants for sulfate displacement of the aqua ligand $\left(k_{\mathrm{L} 1}\right)$ and aquation of the sulfato ligand $\left(k_{\text {-L1 }}\right)$ are both about 2 times lower for 1 than dinuclear $1,1 / t, t$, resulting in similar $\mathrm{p} K_{2}$ values. In stark contrast to the reactions with $1,1 / t, t$, where the rate constant for sulfate displacement of the aqua ligand is about 3 times higher than that of phosphate or acetate, for $\mathbf{1}$ the $k_{\mathrm{L} 1}$ values are similar for sulfate and phosphate. On the other hand, similar to the reaction with $1,1 / t, t$ the aquation of the sulfato ligand is significantly faster (close to an order of magnitude) in comparison to displacement of phosphate.

Reactions of 1 with the D-glucosamine monosaccharide fragments. ${ }^{1} \mathrm{H} /{ }^{15} \mathrm{~N}$ chemical shifts for the $\mathrm{Pt}^{15} \mathrm{NH}_{3}$ and $\mathrm{Pt}_{-}{ }^{15} \mathrm{NH}_{2}$ groups of dichloro (I), aqua (II) and sulfato (III) species observed in all three reactions are similar to those observed for the aquation of $\mathbf{1}$ in sulfate solution (see Table 1). Although the 2- $\mathrm{N}$ and 6-O sulfate environments in GlcNS and GlcNAc(6S) are different, identical chemical shifts are observed for the 2-N- and 6-O-sulfate bound spe- cies, and thus it cannot be determined for GlcNS(6S) (which contains sulfate groups at both 2- $\mathrm{N}$ - and 6-O-positions) whether one or both the sulfate groups are involved in covalent interaction with $\mathbf{1}$.

The time dependence of the concentrations of the species observed in the reactions of $\mathbf{1}$ with GlcNS(6S), GlcNS and Glc$\mathrm{NAc}(6 \mathrm{~S})$ are shown in Figure 2 (b-d). In the case of GlcNS(6S), equilibrium conditions were achieved slightly faster $(9 \mathrm{~h})$ when compared to the reaction of 1 with sulfate $(12 \mathrm{~h})$. There is a marked difference in the equilibrium concentrations with $75.9 \%$ remaining in the chloro form, a similar amount $(22.3 \%)$ in the aqua form but only $1.8 \%$ as sulfate-bound species (Figure $2 b$ ).

Equilibrium conditions were achieved much more slowly for the reactions with GlcNS (93 h, Figure 2c) and GlcNAc(6S) (110 h, Figure $2 \mathrm{~d}$ ) compared to the reactions of $\mathbf{1}$ with either GlcNS(6S) or sodium sulfate, attributed to the slow formation of species in addition to the initial 2- $\mathrm{N}$-sulfate or 6-O-sulfate bound adducts, for which peaks were first visible within $30 \mathrm{~min}$. In the case of GlcNS, two new sets of peaks, first visible after about $2 \mathrm{~h}$ (labeled IV in Figure 1c), have ${ }^{1} \mathrm{H} /{ }^{15} \mathrm{~N}$ shifts $\left(\delta 4.13 /-63.0\left(\mathrm{NH}_{3}\right)\right.$ and 5.02/-47.5 $\left.\left(\mathrm{NH}_{2}\right)\right)$ consistent with $\mathrm{Pt}-\mathrm{N}$ bound species and are attributed to covalent binding of $\mathbf{1}$ with the $\mathrm{N}$-donor of the sulfamate $\left(-\mathrm{NHSO}_{3}\right)$ group. For GlcNAc(6S) a new set of peaks at $\delta 3.97 /-61.1\left(\mathrm{NH}_{3}\right)$ and 4.92/$63.8\left(\mathrm{NH}_{2}\right)$ (labelled $\mathbf{V}$ in Figure 1d) appeared at a similar time and are attributed to binding to the $\mathrm{O}$-donor of the $\mathrm{N}$-acetyl group, based on the ${ }^{1} \mathrm{H} /{ }^{15} \mathrm{~N}$ shift of the $\mathrm{NH}_{2}$ group, which is in the region of $\mathrm{Pt}-\mathrm{O}$ bound species. Interestingly, although GlcNS(6S) also contains a sulfamate group no similar peaks for N-bound species appeared in this case.

Table 3. Rate and Equilibrium Constants for the Aquation and Ligation of $1,0,1 / t, t, t(1)$ with GlcNS $(6 S)$, GlcNS and GlcNAc(6S) (at $298 \mathrm{~K}, \mathrm{pH} \sim 5.4) .^{a}$

\begin{tabular}{lccc}
\hline Parameter & GlcNS $(6 \mathrm{~S})$ & GlcNS & ${\text { GlcNAc }(6 S)^{b}}^{b}$ \\
\hline$k_{\mathrm{H}}\left(10^{-5} \mathrm{~s}^{-1}\right)$ & $3.06 \pm 0.02$ & $3.16 \pm 0.02$ & $2.94 \pm 0.03$ \\
$k_{-\mathrm{H}}\left(\mathrm{M}^{-1} \mathrm{~s}^{-1}\right)$ & $0.217 \pm 0.001$ & $0.284 \pm 0.002$ & $0.132 \pm 0.002$ \\
$k_{\mathrm{L} 1}\left(\mathrm{M}^{-1} \mathrm{~s}^{-1}\right)$ & $0.0018 \pm 0.0003$ & $0.0086 \pm 0.0007$ & $14 \pm 1$ \\
$k_{\mathrm{L} 1}\left(10^{-5} \mathrm{~s}^{-1}\right)$ & $34 \pm 6$ & $41 \pm 4$ & $0.0027 \pm 0.0002$ \\
$k_{\mathrm{L} 2}\left(\mathrm{M}^{-1} \mathrm{~s}^{-1}\right)$ & & $0.000218 \pm 0.000004$ & $0.000142 \pm 0.000008$ \\
$k_{\mathrm{L} 2}\left(10^{-5} \mathrm{~s}^{-1}\right)$ & & $0.59 \pm 0.02$ & $0.85 \pm 0.07$ \\
$\mathrm{p} K_{1}$ & $3.850 \pm 0.003$ & $3.953 \pm 0.004$ & $3.652 \pm 0.009$ \\
$\mathrm{p} K_{2}$ & $-0.7 \pm 0.1$ & $-1.32 \pm 0.06$ & $-1.28 \pm 0.04$ \\
$\mathrm{p} K_{3}$ & & $-1.57 \pm 0.02$ & $-1.22 \pm 0.05$ \\
\hline
\end{tabular}

${ }^{a}$ The rate and equilibrium constants were derived from the kinetic models shown in Scheme 2; for the reaction with GlcNS(6S) rate and equilibrium constants determined by considering the concentration of $\mathrm{GlcNS}(6 \mathrm{~S})$ as $30 \mathrm{mM}$ are given in supporting information. ${ }^{b}$ The two minor peaks observed in the reaction with GlcNAc(6S) (labeled 'o' in Figure 1d) together accounted for 5.4\% of the total species at the equilibrium. These minor products were summed as other products and taken into account in the kinetic fit analysis (Model C, Scheme 2). The forward and reverse rate constants for these species are: $k_{0}\left(\mathrm{M}^{-1} \mathrm{~s}^{-1}\right), 0.0000019 \pm$ $0.0000001 ; k_{-O}\left(10^{-5} \mathrm{~s}^{-1}\right), 0.71 \pm 0.07$ and the equilibrium constant $\left(\mathrm{p} K_{\mathrm{O}}\right)$ is $0.57 \pm 0.06$. 

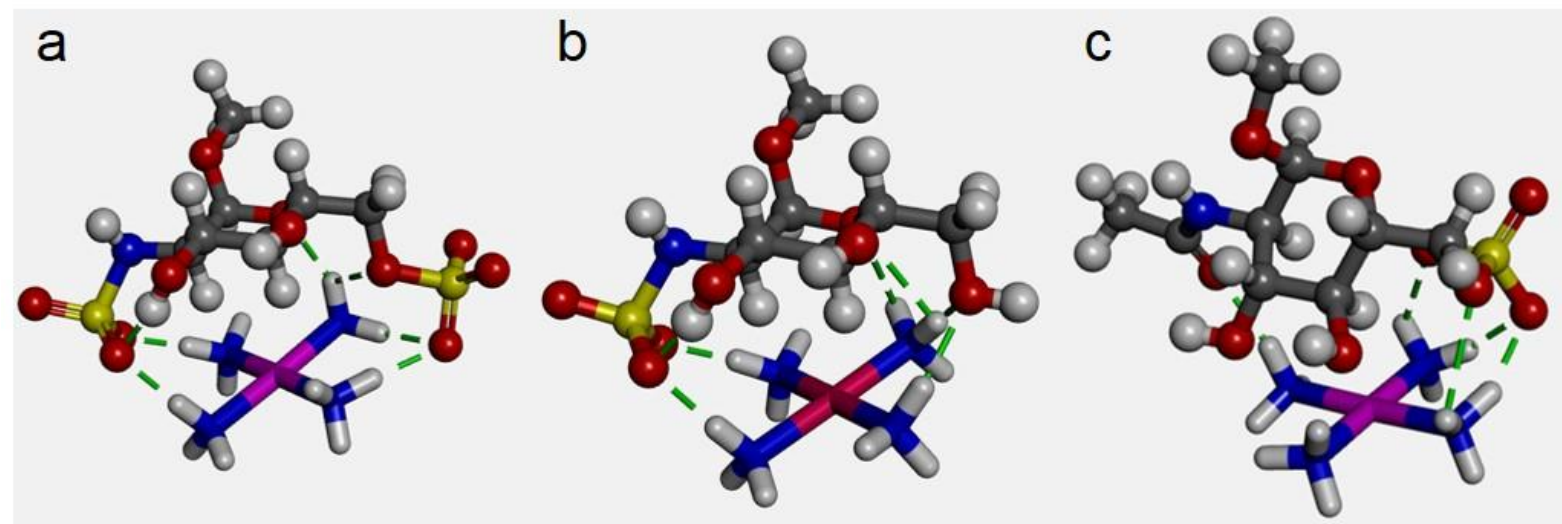

Figure 3. DFT optimized models for the interaction of $\left[\mathrm{Pt}\left(\mathrm{NH}_{3}\right)_{4}\right]^{2+}$ with the sulfated monosaccharide fragments a) GlcNS(6S); b) GlcNS; c) GlcNAc $(6 \mathrm{~S})$.

Rate and equilibrium constants derived using the kinetic models for the respective reactions (illustrated in Scheme 2) are summarized in Table 3. In the case of GlcNAc(6S) the model (C), takes into account the formation of additional minor species which formed slowly over time (peaks labeled "o" in Figure 1d). These peaks were first visible after $6.7 \mathrm{~h}$ and increased very slowly accounting for $2.2 \%$ of the total species at $20 \mathrm{~h}$ and $5.3 \%$ in the equilibrium solution $(110 \mathrm{~h})$. Although unassigned, the species are not due to binding to the monosaccharide as we have observed identical peaks in the reaction of the dinuclear $1,1 / t, t$ with sulfate, where sulfuric acid was used for $\mathrm{pH}$ adjustment. These species are observed to a lesser extent in the reaction with GlcNS (Figure 1c).

Comparison of the $\mathrm{p} K_{1}$ values shows some interesting differences for the initial aquation of $\mathbf{1}$ in the presence of the D-glucosamine monosaccharide fragments. The lower $\mathrm{p} K_{1}$ (in comparison to $1,1 / t, t)$ that was observed for $\mathbf{1}$ in the presence of sulfate is similarly observed for GlcNAc $(6 S)$ due to a similar lowering of the anation $(k$ H) rate constant. On the other hand for GlcNS and GlcNS(6S) the $\mathrm{p} K_{1}$ values are higher (indicating equilibrium toward the parent chloro form) and the anation rate constants are now similar to that for $1,1 / t, t$ in the presence of sulfate. Inspection of the DFT model (Figure 3a) of the interaction of the disulfated GlcNS(6S) with $\left[\mathrm{Pt}\left(\mathrm{NH}_{3}\right)_{4}\right]^{2+}$ illustrates how in this case formation of sulfate clamps, involving both the 2- $\mathrm{N}$ - and 6-O sulfate, would limit the ion pairing between the released chloride and the charged $\left\{\mathrm{PtN}_{4}\right\}^{2+}$ central linker. Why there should be a difference for the monosulfated GlcNS and GlcNAc(6S) is less clear based on the single sulfate clamps formed with $\left[\mathrm{Pt}\left(\mathrm{NH}_{3}\right)_{4}\right]^{2+}$ (representing the central $\left\{\mathrm{PtN}_{4}\right\}^{2+}$ ) in each case (Figure $3 \mathrm{~b}$ and $\mathrm{c}$ ).

Comparison of the rate constants for sulfate displacement of the aqua ligand show preferential binding to $2-\mathrm{N}$-sulfate compared to 6$O$ sulfate; the value of $k_{\mathrm{L} 1}$ is 3 -fold higher for GlcNS compared to GlcNAc(6S), but 0.6 times lower than for binding to sulfate. In the case of GlcNS(6S) $k_{\mathrm{L} 1}$ is lower than for binding to the 2-N-sulfate (5 fold) and 6-O sulfate (1.5 fold) in GlcNS and GlcNAc(6S), respectively. It is 7 -fold lower than for binding to sulfate. When consideration is given to GlcNS(6S) containing two sulfate binding groups (effective concentration of $30 \mathrm{mM}$ ) the lowering of $k_{\mathrm{L} 1}$ is even greater, nearly 15 fold lower than for binding to sulfate (Table S1). Once again electrostatic interaction between the disulfated monosaccharide (2- charge) and the $\left\{\mathrm{PtN}_{4}\right\}^{2+}$ linker, through sulfate clamp formation would limit the covalent binding of the sulfate groups to the terminal $\left\{\mathrm{PtN}_{3} \mathrm{OH}_{2}\right\}$ groups. There are subtle differences also in the rate constant for aquation of the sulfato ligand. For
GlcNS and GlcNS(6S) the value $k_{\text {-L1 }}$ is similar to that of the reaction of sulfate but for GlcNAc(6S) it is 3-fold lower. Thus while binding to $2-N$-sulfate is preferred it is liberated more quickly than binding to the 6-O sulfate.

In the case of GlcNS the rate constant $\left(k_{\mathrm{L} 2}\right)$ for displacement of the aqua ligand by the $N$-donor of the sulfamate group is close to 40 fold lower than that for binding to the $2-\mathrm{N}$-sulfate, but the rate constant for the reverse reaction $\left(k_{-\mathrm{L} 2}\right)$ is also significantly lower (nearly 70 fold) so this species accumulates over time. The distribution of species at equilibrium is: I, $72.4 \%$, II, $15.2 \%$, III, $4.9 \%$, IV, $7.5 \%$. Similarly, for GlcNAc $(6 \mathrm{~S})$ the rate constant $\left(k_{\mathrm{L} 2}\right)$ for displacement of the aqua ligand by the $-O$ donor of the $N$-acetyl group is nearly 20 fold lower than that for binding to the 6- $O$ sulfate, whilst the reverse reaction $\left(k_{-\mathrm{L} 2}\right)$ is 16 fold lower resulting in the equilibrium distribution I, 64.7\%, II, 19.3\%, III, 5.7\%, V, 4.8\% (Figure 2).

Although previous studies involving binuclear complexes of cisplatin with $N$-glycylglycine ${ }^{36}$ and $\alpha$-pyridone ${ }^{37}$ as the bridging ligands showed covalent interaction with the $\mathrm{O}$-donor groups (similar to the $N$-acetyl group of GlcNAc(6S)) the low reactivity observed in the present study demonstrate the weaker nature of $\mathrm{N}$-acetyl $\mathrm{O}$-donors compared to sulfate $O$-donors for the binding with the $\mathrm{Pt}(\mathrm{II})$ center.

\section{DISCUSSION}

Glycosaminoglycans such as heparan sulfate are highly sulfated polysaccharides with variable length, disaccharide sequences and sulfation patterns. ${ }^{12}$ Among the building units of the GAG repeating sequences, D-glucosamine residues act as the key synthons for assembly of these complex biomolecules. The results presented in this study show the strong substitution labile nature of the species formed by the covalent interaction of $\mathbf{1}$ with sulfate $\mathrm{O}$-donors of $\mathrm{D}$ glucosamine residues. This work represents an example of the relevance of glycans in bioinorganic chemistry where, specifically, PPCs may represent a new multifunctional chemotype for interference with heparan sulfate (HS)/enzyme/protein interactions, expanding the potential utility of platinum-based anti-cancer agents from cytotoxic to anti-angiogenic and anti-metastatic. ${ }^{14,}{ }^{16}$ Comparison of the reactions with monosulfated GlcNS and GlcNAc(6S) reveal the higher reactivity of $\mathbf{1}$ with the 2-N-sulfate and also higher substitution-labile nature of $2-N$-sulfato species ( $k_{\mathrm{L} 1}$ and $k_{\mathrm{L} 1}$ are both 3 times higher for 2- $\mathrm{N}$-sulfate than 6-O-sulfate). Significantly lower sulfate binding determined in the case of disulfated GlcNS(6S) suggests that incorporation of a second sulfate group at either the 2- $\mathrm{N}$ or 6-O position makes it less favorable towards covalent interaction, which 
may reflect steric effects of the relatively large but highly flexible trinuclear complex or a greater pre-association of the two molecules due to the higher charge on GlcNS(6S) as noted above. The effects of pre-association on the final products of the covalent interaction are often quite subtle and a relevant example is in the mechanism of formation of long range $\{\mathrm{Pt}, \mathrm{Pt}\}$ 1,4 and 1,6-interstrand DNA-DNA cross-links formed by Triplatin (1) where minor groove pre-association affects both the kinetics and mechanism of the cross-link formation as well as final adduct structure. ${ }^{38}$ Similarly, pre-association is implicated in the intimate mechanism of formation of the unique $5^{\prime}-5^{\prime}$ and antiparallel $3^{\prime}-3^{\prime}$ directional isomers of $\{\mathrm{Pt}, \mathrm{Pt}\} 1,4$-interstrand cross-links. 39,40

The analogy with DNA as template is relevant also when we consider extension of the monosaccharide studies here to the cellular reality of the heparan sulfate polymer. The nature of the template (single-stranded versus double-stranded) affects the kinetics of aquation of the dinuclear $1,1 / t, t$ complex, ${ }^{41}$ which emphasizes further the useful analogy between the helical HS and ssDNA. Extending from the simple individual $O$-donors to multiple donor sites on a more complex polymeric, biomolecular template with multiple possible binding sites raises the possibility that the oligosaccharide polymers are "sinks" for electrostatic and hydrogen-bonding interactions. A strong pre-association could for example result in a lower local $\left[\mathrm{Cl}^{-}\right]$ concentration and allow the albeit weak O-donor substitution reactions to occur even in the presence of the expected high extracellular $\left[\mathrm{Cl}^{-}\right]$concentrations. These features can be examined as we move to longer site-specific oligosaccharides, such as studies by ${ }^{1} \mathrm{H}$ NMR spectroscopy of the interaction of Triplatin with the pentasaccharide Fondaparinux, the highly sulfated synthetic glycosaminoglycanbased fragment used clinically as an antithrombotic agent. ${ }^{17}$ The initial spectral changes are entirely indicative of pre-association of Triplatin on the oligosaccharide skeleton followed by bond formation through displacement of the $\mathrm{Pt}-\mathrm{Cl}$ bond. ${ }^{16,42}$ The spectral changes in the alkanediamine linkers of Triplatin also mirrored those observed upon covalent Pt-DNA bond formation. ${ }^{38}$ The interactions are sufficiently strong to inhibit cleavage of Fondaparinux by bacterial heparinase and mammalian heparanase..$^{14,16}$

HS is a significant participant in major cellular processes through binding to a host of structural and signaling proteins such as growth factors. ${ }^{18}$ HS-protein binding is mediated through electrostatic and $\mathrm{H}$-bonding of positively charged protein residues to the negatively charged carboxylate and sulfate groups on the HS polymer. The 6-O-sulfate of D-glucosamine is intimately involved in recognition of a host of growth factors and formation of stable ternary HS-growth factor-growth factor receptor complexes with welldocumented structurally characterized examples. ${ }^{4345}$ Triplatin inhibits fibroblast growth factor (FGF-2) binding to a biotinylated HS and sub-cytotoxic concentrations also inhibit FGF-2-induced migration of human umbilical vein epithelial cells (HUVECs). ${ }^{21}$ The studies presented here contribute to our understanding of the detailed molecular mechanism of inhibition of growth factor-HS interactions by Triplatin (and PPCs in general) and confirm the utility of the metalloshielding approach to targeting heparin and HS - protein interactions. ${ }^{19,46}$

The results may also have implications for the intimate mechanism of heparan sulfate proteoglycan (HSPG)-mediated cellular accumulation of coordination compounds. ${ }^{47}$ HSPGs act as receptors for highly-charged PPCs, facilitating their cellular accumulation by this unique mechanism of internalization not shared with the mononuclear cisplatin and oxaliplatin. ${ }^{47,48}$ This was shown, firstly, by comparing the cellular accumulation of PPCs in the parental Chinese Hamster Ovarian cell line, CHO-K1, and GAG-deficient CHO-pgsA745 (deficient in the GAG-biosynthetic xylosyltransferase 2 XYLT2 enzyme) cells. ${ }^{47}$ Decreased cellular accumulation of PPCs in the GAG-deficient cell lines translated to significantly decreased cytotoxicity and apoptotic events. ${ }^{47}$ The availability of sitespecific mutants allows the molecular details of the accumulation mechanism to be examined. In this respect, the pgsE-606 CHO mutant is 3-5-fold defective in $\mathrm{N}$-sulfotransferase activity, resulting in an approximate 2-3 fold reduction of the extent of $N$-sulfation. ${ }^{49}$ Preliminary studies show that accumulation of Triplatin is diminished in the $\mathrm{CHO}-$ pgsE-606 cell line, with concomitant reduction in cytotoxicity. ${ }^{50}$ These results are at least consistent with a role for the 2 $\mathrm{NHSO}_{3}$ binding in the mediation of PPC cellular accumulation. Further, GAGs are emerging biomarkers for many tumor types including triple negative breast cancer and ovarian cancers. ${ }^{46,50,51}$ Platinum drugs enter tumor cells by complementary pathways including passive diffusion and active transport such as through the copper transport and/or organic cation transport (OCT) system. ${ }^{48}$ The unique HSPG-mediated accumulation pathway for PPCs such as Triplatin can confer a clinical advantage over the current agents in tumors overexpressing GAGs. Fundamental studies as discussed in this contribution are essential to our understanding of how to exploit cellular accumulation mechanisms with the potential for a new approach to precision medicine for platinums.

\section{CONCLUSIONS}

In summary, at the monosaccharide level, the substituents on the sugar ring of the biologically important D-glucosamine affect the kinetics of aquation and substitution of Triplatin $(1,0,1 / t, t, t$; BBR3464). The general concept of pre-association on a biomolecule followed by "fixation" in a covalent bond-forming reaction is validated in the present studies for GAG fragments, even with formally weak $O$-donors. These interactions will underpin the fundamental molecular description of the HS-Pt(M) complex interaction leading to inhibition of $\mathrm{HS}$ function as well as provide a holistic description of the metabolic fate of metal-based anticancer complexes in general in the complex cellular milieu.

\section{ASSOCIATED CONTENT}

\section{Supporting Information}

The supporting information is available free of charge on the ACS Publications website at DOI: Rate and equilibrium constants for the aquation and ligation of ${ }^{15} \mathrm{~N}-1$ ( $\left.1 \mathrm{mM}\right)$ with GlcNS $(6 \mathrm{~S})(30 \mathrm{mM})$, Scientist models used to fit the kinetic data and Experimental procedures.

\section{AUTHOR INFORMATION}

\section{Corresponding Authors}

*s.berners-price@griffith.edu.au

*m.vonitzstein@griffith.edu.au

*npfarrell@vcu.edu

\section{ORCID}

Anil Kumar Gorle: 0000-0001-7838-2625

Premraj Rajaratnam: 0000-0002-3788-5346 
Chih-Wei Chang: 0000-0002-5009-0302

Mark von Itzstein: 0000-0001-6302-7524

Susan J. Berners-Price: 0000-0002-7129-0039

Nicholas P. Farrell: 0000-0001-7160-7182

\section{Notes}

The authors declare no competing financial interests.

\section{ACKNOWLEDGMENTS}

The work was supported by grants from the Australian Research Council (DP150100308) to SBP, MvI and NPF and in part from NIH (RO1CA78754) to NPF. The DFT study in this work was undertaken with the assistance of resources and services from the $\mathrm{Na}$ tional Computational Infrastructure (NCI), which is supported by the Australian Government. We thank Dr Robin Thomson for careful reading of the manuscript.

\section{REFERENCES}

(1) Hudak, J. E.; Bertozzi, C. R. Glycotherapy: New advances inspire a reemergence of glycans in medicine. Chem. Biol. 2014, 21, 16-37.

(2) Cummings, R. D.; Pierce, J. M. The challenge and promise of glycomics. Chem. Biol. 2014, 21, 1-15.

(3) Codd, R. Metalloglycomics: a new perspective upon competitive metal-carbohydrate binding using EPR spectroscopy. Chem. Commun. 2004, 2653-2655.

(4) Farrell, N. P.; Gorle, A. K.; Peterson, E. J.; Berners-Price, S. J. In Metal Ions in Life Sciences; A. Sigel, H. Sigel, E. Freisinger, Sigel, R. K. O., Ed.; Walter de Gruyter, GmbH, Berlin, Germany, 2018; Vol. 18, pp 109140.

(5) Codd, R.; Irwin, J. A.; Lay, P. A. Sialoglycoprotein and carbohydrate complexes in chromium toxicity. Curr. Opin. Chem. Biol. 2003, 7, 213219.

(6) Codd, R.; Lay, P. A. Chromium(V)-sialic (neuraminic) acid species are formed from mixtures of chromium(VI) and saliva. J. Am .Chem. Soc. 2001, 123, 11799-11800.

(7) Waller, L. N.; Fox, N.; Fox, K. F.; Fox, A.; Price, R. L., Ruthenium red staining for ultrastructural visualization of a glycoprotein layer surrounding the spore of Bacillus anthracis and Bacillus subtilis. In J. Microbiol. Methods, 2004; Vol. 58, pp 23-30.

(8) Rozenberg, G. I.; Espada, J.; de Cidre, L. L.; Eiján, A. M.; Calvo, J. C.; Bertolesi, G. E. Heparan sulfate, heparin, and heparinase activity detection on polyacrylamide gel electrophoresis using the fluorochrome tris(2,2'-bipyridine) ruthenium (II). Electrophoresis 2001, 22, 3-11.

(9) Cheng, T.-T.; Yao, J.-L.; Gao, X.; Sun, W.; Shi, S.; Yao, T.-M. A new fluorescence 'switch on' assay for heparin detection by using a functional ruthenium polypyridyl complex. Analyst 2013, 138, 3483-3489.

(10) Szelke, H.; Harenberg, J.; Krämer, R. Detection and neutralisation of heparin by a fluorescent ruthenium compound. Thromb. Haemost. 2009, 102, 859-864.

(11) Vouras, M.; Schubert, M. The outer sphere association of chondroitin sulfate with polyvalent complex cations. J. Am. Chem. Soc. 1957, 79, 792-795.

(12) Farber, S. J.; Schubert, M. The binding of cations by chondroitin sulfate. J. Clin. Invest. 1957, 36, 1715-1722.

(13) Graham, H. D.; Williams, J. L. Quantitative aspects of the interaction of carrageenan and other hydrocolloids with polyvalent cobalt complexes. J. Food Sci. 1966, 31, 362-372.

(14) Mangrum, J. B.; Engelmann, B. J.; Peterson, E. J.; Ryan, J. J.; Berners-Price, S. J.; Farrell, N. P. A new approach to glycan targeting: enzyme inhibition by oligosaccharide metalloshielding. Chem. Commun. 2014, 50, 4056-4058.
(15) Berners-Price, S. J.; Ronconi, L.; Sadler, P. J. Insights into the mechanism of action of platinum anticancer drugs from multinuclear NMR spectroscopy. Prog. Nucl. Magn. Reson. Spectrosc. 2006, 49, 65-98. (16) Peterson, E. J.; Daniel, A. G.; Katner, S. J.; Bohlmann, L.; Chang, C.-W.; Bezos, A.; Parish, C. R.; von Itzstein, M.; Berners-Price, S. J.; Farrell, N. P. Antiangiogenic platinum through glycan targeting. Chem. Sci. 2017, 8, 241-252.

(17) Petitou, M.; van Boeckel, C. A. A. A synthetic antithrombin III binding pentasaccharide is now a drug! What comes next? Angew. Chem. Int. Ed. 2004, 43, 3118-3133.

(18) Chiodelli, P.; Bugatti, A.; Urbinati, C.; Rusnati, M. Heparin/heparan sulfate proteoglycans glycomic interactome in angiogenesis: Biological implications and therapeutical use. Molecules 2015, 20, 6342-6388.

(19) Weiss, R. J.; Esko, J. D.; Tor, Y. Targeting heparin and heparan sulfate protein interactions. Org. Biomol. Chem. 2017, 15, 5656-5668.

(20) Appleton, T. G.; Berry, R. D.; Davis, C. A.; Hall, J. R.; Kimlin, H. A. Reactions of platinum(II) aqua complexes. 1. Multinuclear (platinum195, nitrogen-15, and phosphorus-31) NMR study of reactions between the cis-diamminediaquaplatinum(II) cation and the oxygen-donor ligands hydroxide, perchlorate, nitrate, sulfate, phosphate, and acetate. Inorg. Chem. 1984, 23, 3514-3521.

(21) Centerwall, C. R.; Goodisman, J.; Kerwood, D. J.; Dabrowiak, J. C. Cisplatin carbonato complexes. Implications for uptake, antitumor properties, and toxicity. J. Am. Chem. Soc. 2005, 127, 12768-12769.

(22) Di Pasqua, A. J.; Goodisman, J.; Kerwood, D. J.; Toms, B. B.; Dubowy, R. L.; Dabrowiak, J. C. Activation of carboplatin by carbonate. Chem. Res. Toxicol. 2006, 19, 139-149.

(23) Di Pasqua, A. J.; Centerwall, C. R.; Kerwood, D. J.; Dabrowiak, J. C. Formation of carbonato and hydroxo complexes in the reaction of platinum anticancer drugs with carbonate. Inorg. Chem. 2009, 48, 1192 1197.

(24) Di Pasqua, A. J.; Goodisman, J.; Kerwood, D. J.; Toms, B. B.; Dubowy, R. L.; Dabrowiak, J. C. Role of carbonate in the cytotoxicity of carboplatin. Chem. Res. Toxicol. 2007, 20, 896-904.

(25) Centerwall, C. R.; Kerwood, D. J.; Goodisman, J.; Toms, B. B.; Dabrowiak, J. C. New extracellular resistance mechanism for cisplatin. J. Inorg. Biochem. 2008, 102, 1044-1049.

(26) Mauldin, S. K.; Plescia, M.; Richard, F. A.; Wyrick, S. D.; Voyksner, R. D.; Chaney, S. G. Displacement of the bidentate malonate ligand from (d,1-trans-1,2-diaminocyclohexane)malonatoplatinum(II) by physiologically important compounds in vitro. Biochem. Pharmacol. 1988, 37, 3321-3333.

(27) Mauldin, S. K.; Gibbons, G.; Wyrick, S. D.; Chaney, S. G. Intracellular biotransformation of platinum compounds with the 1,2diaminocyclohexane carrier ligand in the L1210 cell line. Cancer Res. 1988, 48, 5136-5144.

(28) Mauldin, S. K.; Husain, I.; Sancar, A.; Chaney, S. G. Effects of the bidentate malonate ligand on the utilization and cytotoxicity of platinum compounds in the L1210 cell line. Cancer Res. 1986, 46, 2876-2882.

(29) Appleton, T. G.; Hall, J. R.; Ralph, S. F.; Thompson, C. S. M. Reactions of platinum(II) aqua complexes. 2. Platinum-195 NMR study of reactions between the tetraaquaplatinum(II) cation and chloride, hydroxide, perchlorate, nitrate, sulfate, phosphate, and acetate. Inorg. Chem. 1984, 23, 3521-3525.

(30) Ruhayel, R. A.; Corry, B.; Braun, C.; Thomas, D. S.; Berners-Price, S. J.; Farrell, N. P. Determination of the kinetic profile of a dinuclear platinum anticancer complex in the presence of sulfate: Introducing a new tool for the expedited analysis of $2 \mathrm{D}\left[{ }^{1} \mathrm{H},{ }^{15} \mathrm{~N}\right]$ HSQC NMR spectra. Inorg. Chem. 2010, 49, 10815-10819.

(31) Davies, M. S.; Thomas, D. S.; Hegmans, A.; Berners-Price, S. J.; Farrell, N. Kinetic and equilibria studies of the aquation of the trinuclear 
platinum phase II anticancer agent $\left[\left\{\text { trans- } \mathrm{PtCl}\left(\mathrm{NH}_{3}\right)_{2}\right\}_{2}\{\mu\right.$-trans$\left.\left.\mathrm{Pt}\left(\mathrm{NH}_{3}\right)_{2}\left(\mathrm{NH}_{2}\left(\mathrm{CH}_{2}\right)_{6} \mathrm{NH}_{2}\right)_{2}\right\}\right]^{4+}$ (BBR3464). Inorg. Chem. 2002, 41, 1101-1109.

(32) Zhang, J.; Thomas, D. S.; Davies, M. S.; Berners-Price, S. J.; Farrell, N. Effects of geometric isomerism in dinuclear platinum antitumor complexes on aquation reactions in the presence of perchlorate, acetate and phosphate. J. Biol. Inorg. Chem. 2005, 10, 652-666.

(33) Cai, C.; Dickinson, D. M.; Li, L.; Masuko, S.; Suflita, M.; Schultz, V.; Nelson, S. D.; Bhaskar, U.; Liu, J.; Linhardt, R. J. Fluorous-assisted chemoenzymatic synthesis of heparan sulfate oligosaccharides. Org. Lett. 2014, 16, 2240-2243.

(34) Hu, Y.-P.; Lin, S.-Y.; Huang, C.-Y.; Zulueta, M. M. L.; Liu, J.-Y.; Chang, W.; Hung, S.-C. Synthesis of 3-O-sulfonated heparan sulfate octasaccharides that inhibit the herpes simplex virus type 1 host-cell interaction. Nat. Chem. 2011, 3, 557-563.

(35) Inoue, Y.; Nagasawa, K. An improved method for the preparation of crystalline sodium salts of 2-deoxy-2-sulfoamino-d-glucose and methyl 2-deoxy-2-sulfoamino- $\alpha$-d-glucopyranoside. Carbohydr. Res. 1979, 69, 297-300.

(36) Appleton, T. G. Donor atom preferences in complexes of platinum and palladium with amino acids and related molecules. Coord. Chem. Rev. 1997, 166, 313-359.

(37) Hollis, L. S.; Lippard, S. J. Synthesis, structure, and platinum-195 NMR studies of binuclear complexes of cis-diammineplatinum(II) with bridging .alpha.-pyridonate ligands. J. Am. Chem. Soc. 1983, 105, 3494 3503.

(38) Hegmans, A.; Berners-Price, S. J.; Davies, M. S.; Thomas, D. S.; Humphreys, A. S.; Farrell, N. Long range 1, 4 and 1, 6-interstrand crosslinks formed by a trinuclear platinum complex. Minor groove preassociation affects kinetics and mechanism of cross-link formation as well as adduct structure. J. Am. Chem. Soc. 2004, 126, 2166-2180.

(39) Ruhayel, R. A.; Berners-Price, S. J.; Farrell, N. P. Competitive formation of both long-range $5^{\prime}-5^{\prime}$ and short-range antiparallel $3^{\prime}-3^{\prime}$ DNA interstrand cross-links by a trinuclear platinum complex on binding to a 10-mer duplex. Dalton Trans. 2013, 42, 3181-3187.

(40) Ruhayel, R. A.; Moniodis, J. J.; Yang, X.; Kasparkova, J.; Brabec, V.; Berners-Price, S. J.; Farrell, N. P. Factors affecting DNA-DNA interstrand cross-links in the antiparallel 3'-3' sense: A comparison with the 5'-5' directional isomer. Chem. Eur. J. 2009, 15, 9365-9374.

(41) Davies, M. S.; Berners-Price, S. J.; Cox, J. W.; Farrell, N. The nature of the DNA template (single-versus double-stranded) affects the rate of aquation of a dinuclear Pt anticancer drug. Chem. Commun. 2003, 122 123.

(42) Gorle, A. K.; Katner, S. J.; Johnson, W. E.; Lee, D. E.; Daniel, A. G.; Ginsburg, E. P.; von Itzstein, M.; Berners-Price, S. J.; Farrell, N. P. Substitution-inert polynuclear platinum complexes as metalloshielding agents for heparan sulfate. Chem. Eur. J. 2018, 24, 6606-6616.

(43) El Masri, R.; Seffouh, A.; Lortat-Jacob, H.; Vivès, R. R. The "in and out" of glucosamine 6-O-sulfation: the 6th sense of heparan sulfate. Glycoconj. J. 2017, 34, 285-298.

(44) Faham, S.; Hileman, R. E.; Fromm, J. R.; Linhardt, R. J.; Rees, D. C. Heparin structure and interactions with basic fibroblast growth factor. Science 1996, 271, 1116-1120.

(45) Wesche, J.; Haglund, K.; Haugsten, E. M. Fibroblast growth factors and their receptors in cancer. Biochem. J. 2011, 437, 199-213.

(46) Fuster, M. M.; Esko, J. D. The sweet and sour of cancer: glycans as novel therapeutic targets. Nat. Rev. Cancer 2005, 5, 526-542.

(47) Silva, H.; Frézard, F.; Peterson, E. J.; Kabolizadeh, P.; Ryan, J. J.; Farrell, N. P. Heparan sulfate proteoglycan-mediated entry pathway for charged tri-platinum compounds: differential cellular accumulation mechanisms for platinum. Mol. Pharm. 2012, 9, 1795-1802.
(48) Hall, M. D.; M. Okabe; D. Shen; X. Liang; M.M. Gottesman. The role of cellular accumulation in determining sensitivity to platinumbased chemotherapy. Annu. Rev. Pharmacol. Toxicol. 2008, 48, 495-535. (49) Bame, K. J.; Esko, J. D. Undersulfated heparan sulfate in a Chinese hamster ovary cell mutant defective in heparan sulfate $\mathrm{N}$ sulfotransferase. J. Biol. Chem. 1989, 264, 8059-8065.

(50) Katner, S. J.; Hampton, J. D.; Peterson, E. J.; Katsuta, E.; Sayyad, M. R.; Takabe, K.; Koblinski, J.; Farrell, N. P. Abstract 3941: Heparan sulfate, a new target for platinum in metastatic TNBC. Cancer Res. 2018 , 78, 3941-3941.

(51) Vallen, M. J. E.; van der Steen, S. C. H. A.; van Tilborg, A. A. G.; Massuger, L. F. A. G.; van Kuppevelt, T. H. Sulfated sugars in the extracellular matrix orchestrate ovarian cancer development: 'When sweet turns sour'. Gynecol. Oncol. 2014, 135, 371-381. 


\section{For Table of Contents Only}

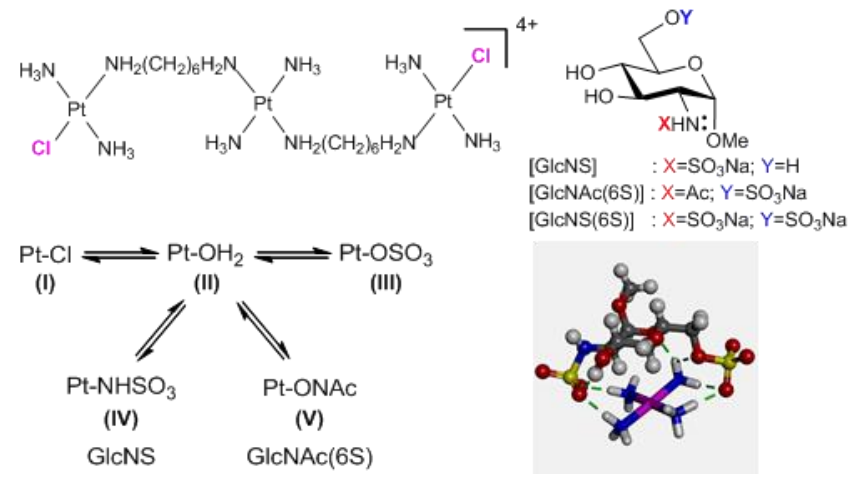

$\left[{ }^{1} \mathrm{H},{ }^{15} \mathrm{~N}\right]$ HSQC 2D NMR spectroscopy has been used to study the aquation and subsequent covalent binding of the trinuclear clinical agent Triplatin with D-glucosamine residues containing varied $O$-sulfate, $N$-sulfate or $N$-acetyl substitutions which represent monosaccharide fragments present within the repeating disaccharide sequences of cell surface Heparan Sulfate. 